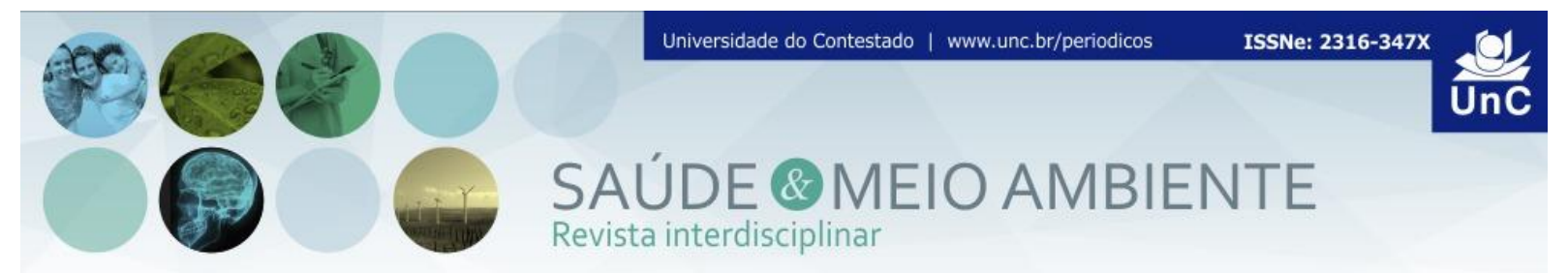

\title{
PREVENÇÃO DE PROBLEMAS POSTURAIS: A IMPORTÂNCIA DO PROFESSOR DE EDUCAÇÃO FÍSICA
}

\author{
Mariana Chicorski ${ }^{1}$ \\ Regiane Paz Müller ${ }^{2}$ \\ Valderi Abreu de Lima ${ }^{3}$ \\ William Cordeiro de Souza ${ }^{4}$ \\ Luis Paulo Gomes Mascarenhas ${ }^{5}$ \\ Marco Antonio Salles Rosa ${ }^{6}$
}

\begin{abstract}
RESUMO
Este estudo teve como objetivo, realizar um levantamento bibliográfico para verificar a importância do professor de educação física dentro das escolas na prevenção de problemas posturais. Realizou-se uma revisão de literatura baseada na consulta às seguintes bases de dados: LILACS e SciELO. Através da literatura pesquisada foi possível verificar que o professor de Educação Física, pode ajudar detectar possíveis alterações na sua postura, bem como, conscientizar, orientar, prevenir, e ainda possibilitar aquisições de hábitos saudáveis, que possam ser redimensionados para toda vida da criança.
\end{abstract}

Palavras-Chave: Postura. Prevenção. Educação Física.

\footnotetext{
${ }^{1}$ Licenciada em Educação Física, Universidade Estadual de Ponta Grossa - UEPG. Paraná. Brasil. Email: valderiabreulima@hotmail.com

${ }^{2}$ Licenciada em Educação Física, Universidade Estadual de Ponta Grossa - UEPG. Paraná. Brasil. Email: williammixx@hotmail.com

${ }^{3}$ Mestrando em Educação Física pela Universidade Federal do Paraná - UFPR. Paraná. Brasil. Email: valderiabreulima@hotmail.com

${ }^{4}$ Universidade Estadual do Centro-Oeste - Unicentro. Paraná. Brasil. E-mail: professor williamsouza@yahoo.com.br

${ }^{5}$ Graduado em Educação Física pela Universidade de Formação e Educação e Cultural do Abc (1993) e mestrado em Atividade Física e Saúde pela Universidade Federal do Paraná (2005). Doutor em Saúde da Criança e do Adolescente. Professor da Universidade Estadual do Centro-Oeste Unicentro. Paraná. Brasil. E-mail: masca58@hotmail.com

${ }^{6}$ Graduação em Licenciatura Em Educação Física pela Universidade Estadual de Ponta Grossa (1977), graduação em Fisioterapia pela Universidade Católica de Petrópolis, especialização em Ciências da Educação Motora pela Universidade Estadual de Ponta Grossa, especialização em Especialização em Gestão Industrial pelo Centro Federal de Educação Tecnológica do PR e mestrado em Engenharia de Produção pela Universidade Tecnológica Federal do Paraná. Paraná. Brasil. E-mail: marcosalles@interponta.com.br
} 


\title{
PREVENTION OF POSTURAL PROBLEMS: THE IMPORTANCE OF THE TEACHER OF PHYSICAL EDUCATION
}

\begin{abstract}
This study aimed, perform a literature review to verify the importance of the teacher of physical education in schools to prevent postural problems. We conducted a literature review based on consultation with the following databases: LILACS and SciELO. Through literature was possible to verify that the physical education teacher, can help detect possible changes in your posture, as well as educate, guide, prevent, and also enable acquisition of healthy habits that can be scaled to any child's life.
\end{abstract}

Keywords: Posture. Prevention. Physical Education.

\section{INTRODUÇÃO}

Nos dias atuais, pode-se perceber o crescente aumento de incidências de problemas relacionados à coluna vertebral (GUEDES; SILVA; SILVA, 2007) . Segundo Sena et al., (2013) a má postura pode ser uma das principais causas de problemas na coluna vertebral, tais como: escoliose lombar, lordose, dores nas costas, dor cervical e artrose na coluna.

Para Valadão, Lima e Barroso (2009) os problemas posturais não somente incapacitam atividades profissionais momentâneas, como também podem se tornar crônicas e afetar a qualidade de vida, sendo assim, a prática de exercícios físicos durante a infância e adolescência poderá ser uma alternativa para prevenir essas complicações.

Estima-se que $80 \%$ da população mundial têm, teve ou terá pelo menos um episódio de dor nas costas e $90 \%$ da população possuem má postura (ORGANIZAÇÃO MUNDIAL DA SAÚDE, 2001). No Brasil, 36\% da população sofrem de doença crônica da coluna (BRASIL. MINISTÉRIO DA SAÚDE, 2011).

O posicionamento inadequado em sentar, dormir, caminhar, trabalhar, carregar objetos, levantar peso, entre outros, acabam exigindo muito da musculatura, muitas vezes excedem os limites que a alavanca lombar suporta, aonde acaba sobrecarregando articulações e discos epifisários (SILVA et al., 2014). Neste sentido, percebe-se a necessidade de uma maior conscientização da população com relação à postura corporal correta diante das atividades do cotidiano (SANTOS et al., 2014).

No entanto, os problemas ortopédicos de origem postural são na maior parte deles advindos da fase de crescimento, onde a coluna da criança ainda é maleável, podendo sofrer alterações (PACENKO et al., 2016). Maus hábitos posturais nesta fase podem acarretar em problemas crônicos na vida adulta (OSHIRO; FERREIRA; COSTA, 2007). 
Diante do exposto, o professor de educação física (EF) poderá contribuir para a prática que hábitos salutares para a qualidade de vida de seus alunos, através da observação este pode detectar alterações posturais já existentes nos seus alunos e orientá-los a tomar as medidas adequadas (RAMOS; RODRIGUES, 2013).

O professor de EF deve exercer um papel de extrema importância, pondo em prática seus conhecimentos acadêmicos, na área da saúde, para promover o bemestar social, traduzindo em uma postura correta (VALADÃO; LIMA; BARROSO, 2009).

Sendo assim, o presente estudo buscou como objetivo verificar a importância do professor de EF dentro das escolas na prevenção de problemas posturais.

\section{MÉTODOS}

O presente estudo trata-se de uma revisão de literatura, segundo Costa (2009) a revisão literatura é a localização e obtenção de documentos para avaliar a disponibilidade de material que subsidiará o tema do trabalho de pesquisa abordado e este levantamento é realizado junto a informações já existentes.

Sendo assim, foram consultadas duas bases de dados: Literatura LatinoAmericana e do Caribe em Ciências da Saúde (LILACS) e Scientific Electronic Library Online (SCIELO), a partir do recurso aos seguintes descritores: postura, estudantes e educação física. Os indexadores para a pesquisa foram selecionados segundo os Descritores em Ciência da Saúde (DeCS/MeSH).

Os critérios de inclusão foram: artigos publicados em português, com os resumos disponíveis nas bases de dados selecionadas e acesso ao texto completo, no período compreendido entre 2001 a 2016. Vale ressaltar que dissertações de mestrado que abordavam o assunto também foram incluídas no estudo (1996 a 1999). Foram excluídos artigos anteriores a 2001 ou publicados em idiomas diferentes do português.

Após o levantamento inicial, os resumos localizados a partir da utilização dos referidos descritores "isoladamente ou combinados" foram lidos e analisados de acordo com os critérios de inclusão e exclusão definidos. Os artigos selecionados, a partir desse procedimento inicial, foram recuperados e analisados na íntegra.

\section{RESULTADOS E DISCUSSÕES}

A escola é um local em que as crianças passam boa parte de suas vidas, muitas vezes sentadas por um bom período, ou realizando atividades físicas e 
psicomotoras (DUARTE et al., 2012). O conhecimento sobre seu corpo no espaço ainda está em construção, assim estimular o desenvolvimento do acervo motor com atividades de sentar, correr, brincar, agachar, pular, manipular objetos, é de suma relevância para a criança possuir um repertório grande de movimentos (RODRIGUES; ABRÃO, 2011).

Sendo assim, Vieira (2011) afirma que a escola possui uma forte influência sobre a construção de atitudes no aluno, pois o convívio escolar propicia transmissões de valores aos alunos; também reforça que a escola por si própria não pode levar ao aluno adquirir saúde, mas pode sim proporcionar elementos que o capacite para uma vida saudável.

Pensando-se na escola como capacitação para uma vida mais saudável, e refletindo sobre o profissional que possui maior identidade para poder realizar um trabalho de prevenção dentro da escola, remetem-se as reflexões ao professor de $E F$, que conforme Verderi (2005) é o responsável pela educação corporal de crianças, jovens e adultos.

Desta forma, o profissional de EF apresenta um papel importante dentro da área escolar, pois o mesmo poderá contribuir na construção postural da criança, na orientação, conhecimento, vigência, acompanhamento, prevenção, e também na detecção de possíveis alterações posturais (cifose, lordose e escoliose) (MARTINS; TUMELERO, 2011; ASSIS, 2014).

Na visão de Valladão, Lima e Barroso (2009) o professor de EF deve através de seus conhecimentos acadêmicos na área da saúde promover o bem-estar social, prevenindo e conscientizando os alunos sobre a importância da coluna vertebral para a sua qualidade de vida, intervindo para uma mudança de hábitos, onde acredita ser importante caminhar juntas: conscientização e mudança de hábitos.

Mediante a realização de um trabalho de educação postural, que pode acontecer nas escolas, por meio de diferentes metodologias, o professor de EF estará proporcionando aos seus alunos 0 acesso a informações que podem contribuir para uma possível conscientização da importância de educar-se posturalmente caso isto ocorra, hábitos posturais inadequados poderão ser evitados bem como o estabelecimento de patologias decorrentes do mau uso da coluna vertebral (RAMOS; RODRIGUES, 2013).

Segundo Teixeira e Vanícola, (2001) os professores de EF precisam de maiores conhecimentos relativos à mecânica corporal, conhecimentos sobre as sobrecargas que a coluna vertebral pode sofrer, sobre o controle da postura, para que possam criar estratégias de uma aula com o foco neste tema. Para estes autores, esta falta de conhecimentos sobre o tema "Postura Corporal" pelo professor de EF, pode ter princípio no próprio currículo de graduação da área, onde ocorre maior ênfase em jogos e atividades esportivas, em detrimento a temas como noções sobre o corpo e cultura corporal.

Com relação à formação do professor de EF Deloroso, (1999) enfatiza que o futuro da qualidade da formação do professor de EF depende de uma permanente atuação, bem como a exigência de níveis mais elevados de qualificação nas 
instituições formadoras, para se buscar formar um profissional que domine amplamente as técnicas de sua área de formação, dentre os conteúdos e habilidades de interesse ao profissional da área, pode-se considerar a importância do estudo e domínio do conhecimento relacionado com as questões do corpo e postura.

No entanto, para Barbosa, (2010) o professor de EF através de disciplinas que fazem parte de seu currículo, como: anatomia, cinesiologia, avaliação e medidas, fisiologia humana, fisiologia do exercício, aprendizagem motora, entre outras, torna-o qualificado para tal. Mas, argumenta que conhecimentos sobre o corpo, e conteúdos relacionados à postura ainda são pouco preferidos pelos professores em suas aulas, portanto, cabendo ao professor redimensionar esta realidade.

$\mathrm{Na}$ atuação do professor de EF na perspectiva da prevenção, Barbosa, (2010) salienta a importância da avaliação postural e antropométrica, onde acredita que cada caso deve ser analisado individualmente, e se necessário ser direcionado a outros especialistas como fisioterapeutas, médicos e psicólogos. Para o autor supracitado, a prática pedagógica deverá estar atenta às individualidades e limites de cada aluno, propiciando uma maior adequação das aulas, tanto com relação à faixa etária, quanto às características de cada um.

Ainda sobre a questão da avaliação e orientação postural Verderi, (2003) discorre da importância da necessidade da implantação de um setor de avaliação e acompanhamento do desenvolvimento motor da criança dentro das escolas, onde os professores possam desenvolver programas de orientação e intervenção imediata em atividades físicas corretivas para os desequilíbrios posturais, avaliações periódicas, orientação para a importância de bons hábitos posturais nas atividades diárias, possibilitando uma boa biomecânica.

Em se tratando de ações intervencionistas e estratégicas nas aulas de EF escolar, Teixeira e Vanícola (2001) discorrem sobre o estímulo às informações sensoriais, através de atividades que estimulem a propriocepção da postura corporal, e ainda remetem-se a importância do feedback do professor aos alunos na realização de tarefas. Nesta perspectiva, encontramos em Santos (1996) também, a reafirmação da importância do aprimoramento da propriocepção através do professor de EF, sem a pretensão de solucionar o problema. Santos (1996) propõe aos profissionais de EF a realização de atividades que proporcionem a seus alunos o aprimoramento da propriocepção, possibilitando a eles o aumento da consciência corporal, consequentemente, a consciência da sua atitude ou postura, facilitando um possível trabalho de reeducação postura.

Teixeira e Vanícola (2001) ainda sugerem aos professores de EF em suas aulas, a utilização de diversos movimentos da coluna vertebral em seus alunos, o que para eles possibilitam uma melhora na consciência corporal, e onde o aluno pode perceber quais movimentos podem lhe causar desconforto, uma forma de perceber seu corpo. Também valorizam estratégias de execução de diversas tarefas que exijam equilíbrio corporal, e que trabalhem juntamente os receptores sensoriais: visual, tátil e auditivo. 
Para Teixeira e Vanícola (2001) tais tarefas podem ser direcionadas no intuito do controle postural, na reeducação do corpo, através de movimentos, consciência do corpo no espaço, equilíbrio, e sensações proprioceptivas. Orientam para que o professor de EF trabalhe de acordo com a faixa etária com que atua, evitando sobrecargas excessivas para a coluna vertebral dos alunos, e utilizem exercícios compensatórios como alongamentos de músculos paravertebrais e exercícios de tração e relaxamento para minimizar as possíveis sobrecargas durante a atividade física.

Barreto e Farina (2009) ressaltam a importância do professor de EF na educação motora da criança e na prevenção de problemas posturais. Argumentam, para tanto, que além de orientações sobre boas posturas, como formas de prevenção, torna-se importante o fortalecimento dos músculos para sustentar o peso e dar suporte à coluna vertebral, o alongamento dos músculos, também trabalhar a resistência muscular, e o relaxamento que é um grande aliado na diminuição da tensão que sobrecarregam os músculos.

\section{CONCLUSÃO}

Através deste estudo, pode-se perceber a importância do professor de EF no que se refere à prevenção de possíveis problemas da coluna vertebral, oriundos da má postura de crianças e adolescentes na fase escolar. Para tanto, o professor de $E F$, sendo ele um dos profissionais que trabalham com a educação do corpo e na formação da imagem corporal, cabe a ele detectar possíveis alterações na sua postura, bem como, conscientizar, orientar, prevenir, e ainda possibilitar aquisições de hábitos saudáveis, que possam ser redimensionados para toda vida da população escolar.

\section{REFERÊNCIAS}

ASSIS, M. Avaliação postural na escola: desvios posturais da coluna vertebral em alunos do $1^{\circ}$ ano do ensino médio. Revista Digital. Buenos Aires. v. 19, n. 191, p. $1,2014$.

BARBOSA, L. M. F. M. G. Educação física escolar como contribuição para prevenção de problemas posturais da coluna vertebral. 2010, $48 \mathrm{f}$. Trabalho de Conclusão de Curso em Educação Física. Universidade Nove de Julho, São Paulo, 2010.

BARRETO, S. J.; FARINA, E. C. R. Contribuições da educação motora para a melhoria e prevenção postural em escolares. Revista Digital. Buenos Aires. v. 13, n. 130, p. 1, 2009. 
BRASIL. MINISTÉRIO DA SAÚDE. Plano Nacional de Saúde - PNS: 2012-

2015/Ministério da Saúde. Secretaria-Executiva. Subsecretaria de Planejamento e Orçamento. Brasília: Ministério da Saúde, 2011. Disponível em:

<http://conselho.saude.gov.br/biblioteca/Relatorios/plano_nacional_saude_2012_201 5.pdf> Acesso em: 23 de set. 2016.

COSTA, A. Metodologia científica. Mafra: Nosde, 2009.

DELOROSO, F. T. O Estudo da Postura Corporal em Educação Física. 1999, 132 f. Dissertação de Mestrado em Educação Física. Faculdade de Educação Física Universidade Estadual de Campinas, Campinas, 1999.

DUARTE, V. B.; FEIJÓ, M. G.; DALPIAZ, G. S. DUARTE, M. G. A importância do ensino e prática da postura correta nas séries iniciais. Revista Digital. Buenos Aires. v. 17, n. 175, p. 1, 2012.

GUEDES, B. N.; SILVA, M. I. T.; SILVA, C. C. A metodologia da problematização na Escola de Posturas da UFPB: um processo emancipatório na prática da educação gerontológica. Revista Eletronica de Enfermagem. v. 9, n. 2, p. 298-314, 2007.

MARTINS, A. M.; TUMELERO, S. Alterações posturais da coluna vertebral, provocadas pelo peso da mochila escolar em crianças e adolescentes. Revista Digital. Buenos Aires. v. 16, n. 156, p. 1, 2011.

ORGANIZAÇÃO MUNDIAL DA SAÚDE. Saúde mental: nova concepção, nova esperança. Genebra - Suíça, 2001. Disponível em:

<http://apps.who.int/iris/bitstream/10665/42390/4/WHR_2001_por.pdf> Acesso em: 23 de set. 2016.

OSHIRO, V. A.; FERREIRA, P. G.; COSTA, R. F. Alterações posturais em escolares: Uma revisão da literatura. Revista Brasileira de Ciências da Saúde. v. 2, n. 13, p. 15-22, 2007.

PACENKO, L. P.; MORALES, P. J. C.; SOUZA, W. C.; MASCARENHAS, L. P. G.; BRASILINO, M. F.; BRASILINO. F. F. A influência do peso da mochila na cifose torácica em escolares. Movimento e Saúde - Revista Inspirar. v. 9, n. 2, p. 37-42, 2016.

RAMOS, A. T. O.; RODRIGUES, N. R. D. Educação Física escolar x educação postural: uma abordagem da realidade em Macapá. Revista Digital. Buenos Aires. v. 17, n. 177, p. 1, 2013.

RODRIGUES, D. B.; ABRÃO, R. K. Habilidades e competências do professor de Educação Física. Revista Digital. Buenos Aires. v. 16, n. 161, p. 1, 2011.

SANTOS, M. R. Explorando as origens dos problemas posturais: Uma revisão bibliográfica. 1996, 45 f. Monografia de Educação Física. Faculdade de Educação Física - Universidade Estadual de Campinas, Campinas, 1996. 
SANTOS, P. J.; OLIVEIRA, A. M.B.; BARBOSA, G. R.; PRAZERES, L. M. A.; FERREIRA, J. Aplicação de uma escola de posturas no município de Lagarto/SE: Um relato de experiência. Cadernos de Educação, Saúde e Fisioterapia. v. 1, n. 1, 2014.

SENA, L. B.; SERAFIM, M. M.; ANDRADE, V. L. B.; SILVA, V. S.; SILVA.; C. G. S. A influência da maturação biológica no desenvolvimento motor em escolares. Revista Digital. Buenos Aires. v. 18, n. 185, p. 1, 2013.

SILVA, M. R.; FERRAZ, L.; MARCHIORI, P. M.; BRAGHINI, C. C.; FERRETI, F.; RECH, A. P.; FERRAZZO, J. F. Autocuidado postural: educação em saúde com adolescentes do meio rural. FisiSenectus. v. 2, n. 2, p. 35-44, 2014.

TEIXEIRA, L. R.; VANÍCOLA, M. C. A Postura Corporal nos Programas de Educação Física. Revista da Escola Superior de Educação Física de Pernambuco. v. 1, n. 1, p. 7-14, 2001.

VALADÃO, R.; LIMA, P. F. C.; BARROSO, A. R. A educação física Escolar na prevenção de deformidades da coluna vertebral. Revista Digital. Buenos Aires. v. 14, n. 131, p. 1, 2009.

VERDERI, E. A importância da avaliação postural. Revista Digital. Buenos Aires. v. 8, n. 57, p. $1,2003$.

VIEIRA, A. C. C. Orientações Posturais Preventivas para Escolares do Ensino Fundamental: Proposta de Inclusão do Tema pelo Programa Saúde na Escola. 2011. 167 f. Dissertação de Mestrado em Ensino em Ciência da Saúde e do Meio Ambiente. Fundação Oswaldo Aranha - Centro Universitário de Volta Redonda, Volta Redonda, 2011.

Artigo recebido em: 08/10/2015

Artigo aprovado em: 12/11/2016 